\title{
High-Frequency Jet Ventilation Is Making Slow Inroads to the Pediatric ICU
}

High-frequency jet ventilation (HFJV) and high-frequency oscillatory ventilation (HFOV) have been used as both elective and rescue therapy for respiratory distress syndrome and other causes of respiratory failure in neonates. Both modalities are thought to enhance ventilation by bulk convection, turbulence, asymmetric air flow velocities, pendelluft, cardiogenic mixing, laminar flow with Taylor dispersion, collateral ventilation, and molecular diffusion. ${ }^{1,2}$ HFJV differs from HFOV in several ways. First, HFJV is used in combination with conventional mechanical ventilation, with invasive ventilation providing PEEP and tidal breaths termed "sighs." ${ }^{" 3,4}$ The jet flow is created by a valve that releases jets of gas into the inspiratory limb through a small cannula centered in the endotracheal tube adapter, with expiration occurring passively. ${ }^{3,4}$ In HFOV, oscillatory pressure is generated through movement of a piston or diaphragm, and both inspiration and expiration are active., ${ }^{3,4}$ Use of HFJV has been traditionally restricted to neonates because their lower lung compliance allows for greater passive exhalation. No studies have compared HFJV and HFOV in subjects with respiratory distress syndrome. ${ }^{5}$ Furthermore, little evidence exists comparing HFJV to conventional mechanical ventilation, ${ }^{6}$ and published literature on HFJV has generally been limited to small case series. ${ }^{7-9}$

In this issue of RESPIRATORY CARE, Miller et $\mathrm{al}^{10}$ report on the use of HFJV in a young pediatric population using a single-center retrospective case series. The subjects are slightly older and more clinically diverse than previously published studies on HFJV. The authors describe how their pediatric ICU uses HFJV as an intermediate mode between invasive ventilation and HFOV and report the effects of HFJV on measures of pulmonary mechanics and gas exchange. In subjects who remained on this ventilator modality, HFJV improved ventilation as measured with both $\mathrm{pH}$ and $\mathrm{P}_{\mathrm{aCO}_{2}}$, but it had minimal effect on oxygenation. Of 35 subjects, $51 \%$ (18) were successfully transitioned from HFJV to invasive ventilation; 15 (43\%) required transition to extracorporeal membrane oxygenation or other high-frequency modalities, and 9 (26\%) did not survive. As the authors note in their discussion, only subjects who tolerated HFJV were analyzed at later end

The authors have disclosed no conflicts of interest.

Correspondence: Brian M Varisco MD, Cincinnati Children's Hospital Medical Center, Department of Pediatrics, Division of Critical Care Medicine, Cincinnati, Ohio 45244. E-mail: brian.varisco@cchmc.org.

DOI: $10.4187 /$ respcare.08797 points, with nonresponders transitioning to other support modalities resulting in survivor bias at these later time points. While there is no reason to believe that adverse events such as pneumo-

See the Original Study on Page 191

thorax would be more likely during HFJV than during conventional mechanical ventilation, the absence of such events is not reported. Lastly, with a median age of 2.9 months, the findings are only applicable to a fraction of the pediatric ICU population.

These comments notwithstanding, this report is an important addition to the literature on HFJV and demonstrates it as an acceptable alternative to HFOV for hypercarbic respiratory failure unresponsive to conventional mechanical ventilation in young infants. As one might expect with a therapy with the same mean airway pressure as invasive ventilation, HFJV does not substantially improve oxygenation, but it does not appear to be detrimental either. Although the authors did not comment on the benefits of HFJV over HFOV, one might imagine that infants treated with HFJV would have reduced sedative and neuromuscular blockade requirements. Future studies on HFJV in the pediatric ICU should compare the change in oxygenation index on HFJV with similar infants receiving conventional mechanical ventilation and possibly HFOV. Additionally, future studies should attempt to determine whether there is an age at which increasing lung compliance makes HFJV ineffective. While a randomized controlled trial of HFJV is unlikely, such data could be collected in a prospective observational manner with propensity matching of subjects at the same or other institutions. The role for HFJV in the pediatric ICU is not yet clearly defined, but thanks to Miller and colleagues, ${ }^{10}$ we now have a starting place.

Andrea R Maxwell Maria Frazier Department of Pediatrics Division of Critical Care Medicine Cincinnati Children's Hospital Medical Center Cincinnati, Ohio

Brian M Varisco

Department of Pediatrics

Division of Critical Care Medicine Cincinnati Children's Hospital Medical Center Cincinnati, Ohio University of Cincinnati College of Medicine Cincinnati, Ohio 


\section{EDITORIALS}

\section{REFERENCE}

1. Evans E, Biro P, Bedforth N. Jet ventilation. Contin Educ Anaesth Crit Care Pain 2007;7(1):2-5.

2. Pillow JJ. High-frequency oscillatory ventilation: mechanisms of gas exchange and lung mechanics. Crit Care Med 2005;33(3 Suppl):S135-S141.

3. Carpi MF. High-frequency jet ventilation in preterm infants: is there still room for it? Respir Care 2017;62(7):997-998.

4. Eichenwald EC, Stark AR. High-frequency ventilation: current status. Pediatr Rev 1999;20(12):e127-e133.

5. Ethawi YH, Abou Mehrem A, Minski J, Ruth CA, Davis PG. High frequency jet ventilation versus high frequency oscillatory ventilation for pulmonary dysfunction in preterm infants. Cochrane Database Syst Rev 2016;2016(5):CD010548.

6. Rojas-Reyes MX, Orrego-Rojas PA. Rescue high-frequency jet ventilation versus conventional ventilation for severe pulmonary dysfunction in preterm infants. Cochrane Database Syst Rev 2015;2015(10):CD000437.

7. Attar MA, Dechert RE, Donn SM. Rescue high frequency ventilation for congenital diaphragmatic hernia. J Neonatal Perinatal Med 2019; 12(2):173-178.

8. Valentine KM, Sarnaik AA, Sandhu HS, Sarnaik AP. High frequency jet ventilation in respiratory failure secondary to respiratory syncytial virus infection: a case series. Front Pediatr 2016; 4:92.

9. Wheeler CR, Smallwood CD, O'Donnell I, Gagner D, Sola-Visner MC. Assessing initial response to high-frequency jet ventilation in premature infants with hypercapnic respiratory failure. Respir Care 2017; 62(7):867-872.

10. Miller AG, Haynes KE, Gates RM, Kumar KR, Cheifetz IM, Rotta AT. High-frequency jet ventilation in pediatric acute respiratory failure. Respir Care 2021;66(2):191-198. 